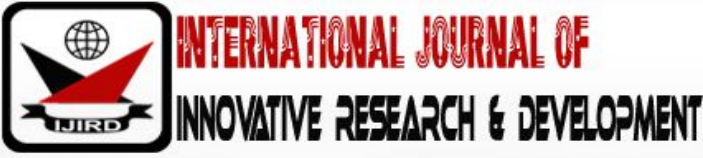

ISSN 2278 - 0211 (Online)

\section{Assessment of Kindergarten Teachers' Use of Learning Activities and Instructional Resources in the Implementation of the Curriculum in Central Region, Ghana}

\author{
Dr. Winston Kwame Abroampa \\ Senior Lecturer, Department of Psychology and Education, University of Education, Winneba, Ghana
}

\begin{abstract}
:
The study assessed kindergarten teachers' use of learning activities and instructional resources in Central Region, Ghana. A descriptive cross-sectional survey which allowed the use of the convergent parallel approach of the mixed method paradigm was employed. Both quantitative and qualitative data were therefore gathered from 1413 using questionnaires, while 10 of them were observed and interviewed. The teachers were randomly selected from ten districts in the Central Region of Ghana. Data were analysed using descriptive statistics. It came to light that KG teachers taught content and used learning activities and resources fairly well. It was however realized that teachers restricted themselves to the use of a few activities due to inadequate materials. The provision of appropriate resources, periodic in-service training and posting of teachers with a background in early childhood education to kindergartens were recommended.
\end{abstract}

Keywords: Kindergarten, learning activities, instructional resources, curriculum implementation

\section{Background of the Study}

Most longitudinal research conducted over the years such as the High Scope Perry Preschool study of lifetime effects and the Abecedarian study that began in 1970s stressed the positive effects of early education, care and support services on later life of children. Lunenburg (2000) and Barnett (2008) agreed that interest in children's early years, especially the first five years, has developed as studies have shown that appropriate programmes for young children can make a difference in their academic, economic, and social life. It has therefore become widely accepted that early school experiences prepare children academically and socially for further educational journey and also lowers repetition and drop-out rates. The benefit is felt mostly by children in the poorest communities (Rao \& Pearson, 2009). Consequently, most countries all over the world, including Ghana have developed and introduced various kinds of early childhood education interventions.

An early childhood education curriculum is aimed at the whole child. Children learn to take risks and solve problems, develop relationships, explore new concepts, acquire some academic skills and knowledge, and enhance their physical, social and emotional competence. They thus need sufficient time to become involved in projects and investigations to satisfy their own interests (Massachusetts Department of Elementary and Secondary Education, 2008). In order for early learners to maximise use of blocks of interactional periods made available, they must be exposed to developmentally appropriate learning resources and learning activities which make use of their social nature, imagination and creativity in a rich learning environment. Children benefit enormously from rich, multi-sensory learning environments that support different learning styles and kinds of intelligence. They acquire symbolic thought as they represent their ideas and knowledge through drawing, painting, block constructions, dramatic play, speaking, and writing. Without these, learning for early learners becomes like schooling at higher levels.

Globally, early childhood educators are expected to be trained and well equipped with the requisite skills and competencies. This has necessitated the running of certificate, diploma and degree programmes in three public universities and seven colleges of education in Ghana for a few years now. A lot still remains to be done since most kindergarten classrooms are still occupied by non-professionals. Effectively transmitting learning experiences however is highly contingent on various learner activities used and the availability of adequate resources. Learning activities are the variety of strategies provided by a teacher in order to engage, stimulate and sustain a learner or group of learners' interest and participation in an interaction to facilitate the acquisition of relevant knowledge, skills and attitudes that would result in learning. Felder (2010) suggests that for the sake of maintaining learners' interest, and facilitating meaningful, and eventually self-directed learning, it is more rewarding to vary teaching and learning activities employed in the classroom. The kindergarten curriculum for 
Ghanaian pupils and teacher's guide for the various content areas provide various relevant activities such as the use of play songs, games, object identification and descriptions among others that pupils can be exposed to.

Activities learners are taken through become worthwhile when relevant learning resources are provided. Thus, in order for early learners to maximise benefits of interacting with and manipulating teaching and learning resources, practitioners need to be able to involve them in relevant activities and experiences. This requires a great deal of skill and creativity on the part of practitioners or teachers. In order to make learning worthwhile for early learners, Herr and Larson (2000) contend that it is important that all curricula be adapted to match the developmental needs of children at a particular age or stage of development since an activity that is appropriate for one group of children may be inappropriate for another. Providing early learners an opportunity to make choices among a wide variety of activities and resources that stimulate their natural curiosity is crucial. It is in this vein that the kindergarten curriculum provides pupils with varying expressive activities that demand their participation in all learning (Ministry of Education, Ghana, 2004). Because the curriculum has been integratively designed, these activities can be used across various content areas and may also be employed concurrently with others in order to achieve maximum results.

The availability of relevant teaching and learning resources is however indispensable to planning worthwhile learning activities for early learners. They indeed play a critical role in the implementation of any educational programme; an early childhood education curriculum in particular. Without resources, teaching and learning is abstract, sterile and largely remains like what prevails at higher levels of education. Though, the kindergarten curriculum and teacher's guide suggest various resources teachers in Ghana could use, Ahmed (2014) in a qualitative study winneba indicates that the inadequate supply or provision of these instructional materials posed a challenge to the effective implementation of early childhood education programme in Ghana thereby making teaching cumbersome.

The unavailability of resources relevant for effective teaching and learning has been the bane of the implementation of educational programmes for which the early childhood education programme in Ghana is no exception. Chisholm (2005) considers inadequate resources as a barrier to curriculum implementation. He identifies the four main resources required as time, materials, resources, administrative support and expertise. He further contends that, material resources present few problems, provided the curriculum designers make a thorough inventory of what is required and budget accordingly, and the institution provides the necessary funds, facilities, equipment and materials. However, in the real world these requirements are often unmet. This situation will obviously compel practitioners to teach what they can teach for learners to learn what they can learn. In the absence of these resources, children are forced to, most often than not, sit quietly like miniature adults and listen to teachers call out alphabet and numbers for them to repeat.

Further, ILO (2012) report on early childhood education reveals that early childhood education in sub-Saharan Africa is often provided in unsuitable premises lacking basic learning resources such as books, toys and other relevant materials. A rather worrying situation is the fact that in a study involving final year pre-service early childhood education teachers conducted by Kankam and Abroampa (2016), the responses suggested that pre-service teachers seem to have a better idea and understanding about the use of traditional teaching techniques rather than the use of integrative, cooperative and experiential learning approaches more relevant for early learners.

Especially for early learners, research (McCombs, \& Miller, 2009) show that child-centred and activity-based learning at the kindergarten KG stage of education is essential for children to reach their full academic potential in later phases of education. Resnick (2008) also regrets that for nearly 200 years, since the first kindergarten opened in 1837, kindergarten has been a time for telling stories, building castles, drawing pictures, and learning to share. However, it looks as if that has changed. Today, more and more kindergarten children are spending time filling out phonics worksheets and memorizing math flashcards. This study therefore sought to assess the instructional resources and learner activities employed by kindergarten teachers in Central Region, Ghana to enable them implement the kindergarten curriculum.

\section{Purpose and Research Questions}

The thrust of the study was to examine kindergarten teachers' use of learner activities and instructional resources in the teaching of various content areas of the kindergarten curriculum in Central Region, Ghana. The study was thus driven by the following;

- How are kindergarten teachers teaching content areas in the kindergarten curriculum?

- How are kindergarten teachers' using learning activities?

- How are kindergarten teachers using instructional resources?

\section{Methodology}

The study employed the convergent parallel design as it examined early childhood educators' use of learner activities and learning resources in the teaching of various content areas of the kindergarten curriculum. This allowed the gathering of complementary data on the same problem to best understand it (Creswell \& Clark, 2011). More analysis, specifically through qualitative data collection, was used to refine, extend, or explain the general picture (Creswell, 2012). It also helped to compare and contrast quantitative statistical results with qualitative findings for corroborations and validation purposes (Creswell \& Clark, 2011). A good amount of responses from a wide range of kindergarten teachers was thus gathered using questionnaires, interview and observation for analysis. This helped to describe, observe and documented aspects situations (teaching) as it naturally occurred rather than explaining it. 
All kindergartens teachers of public basic schools in the Central region of Ghana constituted the target population. Teachers from 492 randomly selected kindergartens in ten selected districts were sampled for the study. Since in some cases there were only two teachers in some schools, all the teachers found in each school were involved. In all 1489 KG teachers were used for the study. Ten teachers - one teacher from a selected school in each of the ten districts - who are part of the sample, were conveniently selected for observation and interview for 20 to 30 minutes. Research assistants and circuit supervisors in selected districts assisted in the administration of questionnaires and retrieval while observation and interviews were conducted by researcher himself.

The questionnaire was a four-point likert-type scale which was coded 4-very well; 3-fairly well; 2-poorly and 1-not at all. It was pretested using $30 \mathrm{KG}$ teachers in Western Region. The content validity and reliability of the instruments were determined through expert review of items and the use of the Cronbach Coefficient alpha which generated alphas of .765 for items on kindergarten curriculum content areas; .685 for use of learner activities and .802 for learning resources. Reliability of observation and interview guide were ascertained by employing the trustworthiness criteria. In all data were analysed from 1413 KG teachers. Descriptive statistics were used in analysing research questions. Qualitative data were recorded, transcribed and reported in narratives to further expand and explain quantitative data.

\section{Results and Discussion}

This part covers the analyses and interpretation of data elicited from KG teachers with the questionnaire, observation and interview guide. The following keys have been used to represent the scales in the tables below; NA-not at all, PL-poorly, FW-fairly well, and VW-very well. Data were interpreted using means and the following mean ranges: NA 1.00-1.49; PL 1.502.49; FW 2.50-3.49; VW 3.50-4.00.

\begin{tabular}{|c|c|}
\hline Content Areas & Mean \\
\hline Language And Literacy & 3.53 \\
Environmental Studies & 3.61 \\
Mathematics & 3.63 \\
Creative Activities & 3.44 \\
Physical Development & 3.36 \\
Psychosocial Skills & 3.32 \\
\hline
\end{tabular}

Table 1: KG Teachers' Ability to Teach Content Areas of the Curriculum

Data in Table 2 demonstrate the views of KG teachers on how they were teaching the six content areas of the KG curriculum. The data reveal that of all the six areas, KG teachers consider number work or mathematics as the aspect they are teaching very well as portrayed by the mean of 3.63. This is followed by environmental studies and language and literacy which generated means of 3.61 and 3.53 respectively. These show that they could teach these subjects very well. The teachers however, did indicate that they are able to expose kindergarteners to psychosocial skills, physical development and creative arts fairly as depicted by their means. In sum, the responses from KG teachers reveal that they are teaching all the six content areas fairly well as suggested by the aggregate mean of 3.48 .

Observation and interviews provided information on teachers' ability to teach various components or content areas of the KG curriculum. It came to light during the lesson observation that most teachers demonstrated much ability in teaching number work, language and literacy and environmental studies. As a result, most teachers opted to teach them leaving creative arts and physical development which was not taught by any teacher. Teachers are expected to expose learners to psychosocial skills by integrating them in lessons they teach by using various techniques and strategies. Most of the teachers opted to teach these subjects probably because they appeared on the time table everyday unlike the others. The follow-up interviews partially confirmed the observations made. When asked how well they were teaching various components of the curriculum, some of them had this to say;

- T2: I'm able to teach almost all of them well but sometimes because the children are slow so I'm not able to teach everything. So, when I'm teaching one subject they learn other things too. Like in maths, we can do a bit of creative arts becausein the KG we do a lot of drawing...and also during language and literacy when I use the conversational poster they learn a lot about the environment.

- T3: I'm able to teach all of them fairly well. I'm supposed to teach about four subjects everyday but because they are children I'm able to do three exercises and even sometimes two on worship days. My problem is that the time for each subject on the time table is short.

- T6: I'm able to teach all of them fairly well. Most of the themes like shapes and colours cut across all the various subjects. So, it makes it easy to teach many things during a particular lesson.

These reflect the opinion of most of the teachers. Most of them indicated they had the ability to teach the various components but inadequate instructional time and the pupils' pace of learning posed a challenge. However, the integrative nature of the curriculum made it possible for them to expose learners to other experiences while teaching. On the other hand, when asked which of the areas they found challenging and needed more information and training, most of them indicated 
physical development, psychosocial skills and creative arts since most of them did not have a background in early childhood education. Another teacher also mentioned that training is needed on how to deal with children who turned alphabets upside down. This basically has to do with children with learning difficulties such as dysgraphia and dyslexia.

It may be inferred from the foregoing that generally kindergarten teachers indicated they are teaching the various content areas fairly well, they however needed more training and information on physical development, psychosocial skills and creative arts. It appears kindergarten teachers are used to teaching number work, language and literacy and environmental studies because they feature on the timetable throughout the week. The absence of requisite teaching learning resources coupled with inadequate teachers with the required expertise to teach makes it cumbersome exposing early learners to physical development activities, psychosocial skills and the creative arts which are more interactive and will explore learners' social, imaginative and creative nature. This has unfortunately made the kindergarten programme more academic.

Kindergarten teachers' claim that they are teaching the various components fairly is deemed to have positive implications for the implementation of the kindergarten curriculum. This might have been borne out of the fact that a vast majority of the teachers were professional teachers, though, only a few of them have been specially trained to teach kindergarteners. They thus considered themselves as having the requisite competencies and skills to teach. The findings agree with Stanley's (1991) conviction that teachers' knowledge of the content or subject matter leads to their competence and effectiveness, and that the effective implementation of an instructional programme and the competence of a teacher are contingent on their firm knowledge of the subject matter. It also supports Abroampa's (2008) assertion that the successful implementation of any educational programme, to a large extent, rests on the shoulders of qualified and competent teachers. This lends credence to Ghazi and Shahzada and Shauib (2013) view that a teacher competent in his profession has a thorough knowledge of subject matter or knowledge of contents. The teacher who has command over subject matter can provide more information and experiences for learners in the classroom.

Conversely, it appears most KG teachers' inability to effectively expose learners to psychosocial skills, physical development activities and the creative arts may be attributed to their background in basic education rather than early childhood education. The early childhood education programme in Ghana provides prospective teachers with specialized training to enable them teach learners in nurseries and kindergartens. The former (basic education) does not, hence their inability to effectively handle these content areas. It appears this is what has made early childhood education more academic since it is these three areas that are more loaded with skills, values and attitudes or affective skills relevant for the total development of early learners. This confirms the finding of Lemaire, Amoah, Ntsiful, Micah \& Bonney (2013) that some stakeholders perceive that teaching at the kindergarten can be done by any teacher whether the person is a professional teacher or not as a result some officials at the District, Municipal or Metropolitan Education Offices post teachers who did not specialize in Early Childhood Education to teach at that level. They assert that even though such teachers are trained, they lack the skills and methodologies for handling kindergarteners. Such teachers thus become frustrated in the classroom and do not know exactly what to do. This adversely affected the implementation of Early Childhood Education Programmes and Policies. It also supports Jinapor's (2014) finding that teacher quality was a challenge facing the implementation of the early childhood education programme in Winneba. McCubbin's (2004) contends that early childhood education curricula have become more academic, suggesting that there is an overemphasis on the development of the cognitive leaving the affective which is influenced by the development of psychosocial and human relationship skills in children. This may probably be because teachers do not have the requisite competencies and expertise. Such a situation certainly has negative implications for the implementation of the kindergarten curriculum and the total development of learners.

Table 2 presents data on teacher learner activities used by kindergarten teachers

\begin{tabular}{|c|c|}
\hline Teacher Learner Activities & Mean \\
\hline Sound/ action cards & 3.38 \\
Picture games & 3.33 \\
Play songs & 3.49 \\
Learning corners & 3.14 \\
Picture reading & 3.54 \\
Pictures identification & 3.54 \\
Puzzles & 2.89 \\
Matching objects & 3.51 \\
Nature walk & 3.37 \\
Pictures description & 3.45 \\
Building pictorial representations & 3.27 \\
Assembling of objects & 3.33 \\
Self and object description & 3.42 \\
\end{tabular}

Table 2: KG Teachers' Use of Teacher Learner Activities

Mean Ranges: NA 1.00-1.49; PL 1.50-2.49; FW 2.50-3.49; VW 3.50-4.00 
Data from Table 2 illustrate that KG teachers are using picture reading and picture identification very well. This is denoted by the mean of 3.54. The next highest means of 3.51 and 3.49 similarly suggest that they are getting kindergarteners to match objects and also use play songs as learning activities very well and fairly well during lessons. Teachers considered the use of puzzles as the least of the activities they are using with early learners during lessons. They were however of the opinion that they are using all the various teacher learner activities fairly well as reflected by the cumulative mean of 3.36.

Data from observation and interview data gathered in connection with activities used have been discussed below. Two items on the observation guide elicited responses from teachers on activities used with pupils and whether they were logically organised. The lessons observed disclosed that teachers mostly used activities involving play songs, picture identification, matching of objects and picture description. This was consistent with results from questionnaire. The use of these activities was timely and were also organised sequentially by teachers who used them. They were mostly teachers directed and not learner-initiated activities.

Responses provided by almost all the teachers interviewed supported the fact that they used a lot of play songs, pictures and other activities to help stimulate and sustain pupils' interest during their lessons. Some teachers had this to say.

- $\quad$ T5 indicated that: Usually I use activities and songs relevant to the topic.They feel very happy when they sing and dance. This helps them to learn faster.

- T6 said that: I use a lot of rhymes and songs for children. If they know how to sing a song the words stick in for a very long time. Some other times too I use activities if the materials are enough after giving them a few clues.

Data gathered with all the three instruments suggest that kindergarten teachers use play songs, picture reading and identification in teaching pupils. These are considered very significant to the instructional process in an early childhood classroom. Since learners at this level are very active, fidgety and have short attention span using activities that will get them actively involved in lessons are highly recommended. However, it looked as if the activities were restricted to only these few ones and were mostly teacher selected activities. The implication is that the inadequate resources made it difficult for KG teachers to use varying instructional activities. This might therefore, not make learning as interactive and experiential as it should be for learners and can serve as a barrier to curriculum implementation (Chisholm, 2005). Resnick (2008) also testifies that since the establishment of the first kindergarten, leaning at that level has been a time for experiential activities. But it looks as if that has changed. In recent times, more kindergarten children are spending time filling out phonics worksheets and memorizing math flashcards. Kankam and Abroampa (2016) suggest that this situation might be due to pre-service early childhood educators' lack of understanding about the use of integrative, cooperative and experiential learning approaches since the degree programme in early childhood education did not make much provision for that.

Table 3 presents data on instructional resources used by kindergarten teachers

\begin{tabular}{|c|c|}
\hline Instructional Resources & Mean \\
\hline $\begin{array}{c}\text { Moulding and modeling } \\
\text { materials e.g. Play dough }\end{array}$ & 3.00 \\
\hline $\begin{array}{c}\text { Drawing and colouring } \\
\text { materials }\end{array}$ & 3.51 \\
\hline $\begin{array}{c}\text { Painting materials eg. } \\
\text { poster colours and brushes }\end{array}$ & 3.10 \\
\hline Writing materials eg. \\
pencils, sand trays, chalk & 3.49 \\
\hline $\begin{array}{c}\text { Sewing, lacing and } \\
\text { threading materials eg. } \\
\text { beads, thread }\end{array}$ & 2.77 \\
\hline $\begin{array}{c}\text { Folding, joining and } \\
\text { trimming materials }\end{array}$ & 2.88 \\
\hline Weaving materials & 2.71 \\
Materials for musical \\
instruments & 2.86 \\
\hline $\begin{array}{c}\text { Materials for physical } \\
\text { exercises rope, tyres }\end{array}$ & 2.98 \\
\hline $\begin{array}{c}\text { Counting materials Reading } \\
\text { materials Picture making } \\
\text { materials Television sets } \\
\text { Computer (s) }\end{array}$ & 3.51 \\
& 3.15 \\
& 1.70 \\
\hline Table 3: KG Teachers' Use of \\
Instructional Resources \\
Mean Ranges: NA 1.00-1.49; PL 1.5 \\
0-2.49; FW 2.50-3.49; VW 3.50-4.00
\end{tabular}


Data in Table 4 is meant to present the responses of KG teachers on how they are using teaching and learning resources. It is evident that of all the fourteen resources, majority of the KG teachers responded favourably to the fact that they were using counting, drawing and colouring materials very well thereby generating a mean of 3.51. Writing materials such as pencils, sand trays etc were the next group of resources most of them were able to use fairly well. This produced a mean of 3.49. Again, most teachers are using reading materials fairly well as indicated by the mean of 3.42. However, a close look revealed that majority of the teachers used television sets and computers poorly and were the least used as shown by the mean of 1.70 and 1.74 respectively. Generally, teachers' responses yielded an aggregate mean of 2.91 suggesting that they are using the resources fairly well.

It is evident from the lessons observed that most of the teachers used some instructional resources which may be considered appropriate for learners. This made some lessons activity oriented and enables learners to participate. Some of the resources used were counting materials such as bottle tops, pebbles and shells. Objects and empty cans of different sizes and shapes were employed while picture cards were also used. It was however noted that in almost all cases the resources were woefully inadequate considering the number of pupils in class and there were no varieties. As a result, a lot of pupils were found crowded around a few resources if they were in groups making some of them inattentive. This affected class control. On the other hand, a few teachers also used only chalkboard illustrations and posters while teaching. Learners only participated by repeating whatever the teacher asked them to say after them. This may be due to unavailability of needed resources. This was further interrogated in the interview with teachers.

The interview sought to elicit reactions relative to the adequacy and instructiveness of resources for teaching kindergarteners. Opinions about resources were varied. Whereas some sounded frustrated about the situation others expressed some level of satisfaction with what are available. For instance:

- T5 replied that: I have a lot of resources but I think I still need more and variety to make lessons more interesting...

- T6 submitted: I was fortunate to have come to meet some of them, for example their work books and some pictures. I have also done a lot myself so I think they are very adequate.

Though, expressions suggest that some teachers are quite satisfied with the resources available and have been able to improvise the ones that are not there, others feel very frustrated and disturbed with the paucity of resources available since it seems to be making teaching and learning difficult. The following responses portray that.

- T2 lamented that: The resources are not there you could see I didn't have a lot of TLMs so I improvised with some leaves so everyone can be engaged in the activity. We have bottle tops but they are not enough. For instance, at KG 1 we need a sand tray. Infact the materials are not there and it's not everything that you can improvise.

- T10 agrees by saying that: As for the resources they are not there at all. It is either we improvise or sometimes fall on what the interns leave for us aftertheir teaching practices.

These responses seem to contradict teachers' claim from results deduced from data gathered with the questionnaire that they are able to use the resources fairly well. From the observation and interviews conducted it was obvious that materials used by KG teachers were woefully inadequate and since some of them cannot be improvised they have to use sketches, pictures and chalkboard illustrations. Information from some teachers further revealed that since distribution of materials were made from the inception of the programme years ago, there has not been any. Therefore, most schools do not have textbooks, workbooks, teachers' guides and manuals.

The unavailability of teaching learning resources has the potential of inhibiting the successful implementation of the curriculum since the resources facilitate the entire instructional or learning process and it may be required at every segment of a lesson especially with early learners. Its availability and adequacy may influence lesson review of previous knowledge, introduction, lesson delivery, learner engagement, classroom management, learning activities employed and assessment of learning. Chisholm (2005) considers the non-availability of resources as the bane of curriculum implementation. ILO (2012) report on early childhood education also disclosed that early childhood education in sub-Saharan Africa is often provided in unsuitable premises lacking basic learning resources such as books, toys and other relevant materials. The findings further reaffirm the findings of Lemaire et al. (2013) and Jinapor (2014) that the inadequate supply of instructional materials posed a challenge for the effective implementation of the early childhood programme in Ghana. Lemaire et al intimate that the successful implementation of early childhood programmes depend to a large extent on the level of availability of instructional materials.

\section{Recommendations}

- It was evident that kindergarten teachers are teaching the various content areas fairly well except that some have challenges exposing early learners to psychosocial skills, physical development and the creative arts because they do not have a background in early childhood education. Planned periodic in-service training and refresher courses organised for kindergarten teachers by the district education directorate of the Ghana Education Service to enable them become abreast of current trends and strategies in the discipline would go a long way to mitigate these deficiencies. 
- $\quad$ More so, the district education directorate should liaise with government and other Non-Governmental Organizations working in early childhood education to provide adequate and up to date teaching and learning resources for kindergartens and training in how to use them in activities since the study revealed that their absence restricted KG teachers to the use of a few resources and activities. Besides, without the resources learners cannot be engaged in meaningful activities which strongly predict the teaching of content areas.

- District education directorates should endeavour to post newly trained teachers with a background in early childhood education to kindergartens to help prepare early learner well in order to build a solid foundation for the rest of schooling. They should not be deployed to teach at higher levels like the Junior High schools simply because they have diplomas and degrees.

\section{References}

i. Abroampa, W.K. (2008). Assessing the challenges in the implementation of the Religious and Moral Education programme: The case of selected Teacher Training Colleges in Ghana. Unpublished Mphil thesis. University of Cape Coast

ii. Barnett, W. S. (2008). Preschool education and its lasting effects: Research and policy implications. Boulder and Tempe: Education and the Public Interest Center \& Education Policy Research Unit

iii. Chisholm, L. (2005). The Making of South Africa's National Curriculum Statement. Journal of Curriculum Studies, 37(2), 193-208

iv. Creswell, J.W. \& Clark, V.L.P. (2011). Designing and conducting mixed methods research.London: Sage Publications Ltd

v. Creswell, J.W. (2012). Educational research. Planning, conducting and evaluating quantitative and qualitative research. Boston: Pearson Education Inc

vi. Felder, R. (2010). Classroom learning activities. Somerville: Center for the Enhancement of Learning and Teaching

vii. Fraenkel, J. R., Wallen, N. E. \& Hyun, H.H. (2012). How to design and evaluate research in education. New York: McGraw Hill Inc.

viii. Ghazi, S.R., Shahzada, G., Shah, T. \& Shauib, S. (2013). Teacher's Professional Competencies in Knowledge of Subject Matter at Secondary Level in Southern Districts of Khyber Pakhtunkhwa, Pakistan. Journal of Educational and Social Research. 3 (2)

ix. Herr, J. \& Libby-Larson, Y.R. (2000). Creative resources for the early childhood classroom. New York: Delmer Thompson Learning

x. ILO (2012). Right beginnings: Early childhood education and educations. Geneva. International Labour Organization

xi. Ahmed, A. (2014). Challenges facing early childhood education in Ghana. What do stakeholders say? Advances in social science research Journal. Vol.1, no 3

xii. Kankam, G. \& Abroampa, W.K. (2016). Early childhood education pre-service teachers' pedagogical content knowledge in teaching psychosocial skills across the kindergarten curriculum in Ghana. Asia Pacific Journal of Research in Early Childhood Education. (10) 1,67-86

xiii. Lemaire, M.B., Amoah, D.F., Ntsiful, D.K. Micah, S. A. \& Bonney, E.A. (2013). Early childhood education in Ghana: Perceptions of stakeholders in the Western Region of Ghana. Journal of Education and Practice. 4 (9), 1-13

xiv. Lunenburg, F.C. (200). Early childhood education programs can make a difference in academic, economic and social arenas. Questia online research. http/ www.questia.com

xv. Massachusetts Department of Elementary and Secondary Education (2008). Kindergarten learning experiences. Malden: MDESE

xvi. Ministry of Education (2004). Curriculum for kindergarten. (1-2). Accra: Ministry of Education, Ghana

xvii. McCombs, B. L., \& Miller, L. (2009). The school leader's guide to learner-centered education: From complexity to simplicity. Thousand Oaks, CA: Corwin Press

xviii. McCubbins, J. L. (2004). Transition into kindergarten: A collaboration of family and educational perspectives. Unpublished master's thesis, Virginia Polytechnic Institute and State University, Blacksburg

xix. Rao, N. and Pearson, V. (2009). Early childhood education in Cambodia. International Journal of Child Care and Education Policy. (3) 1, 13-26

xx. Resnick, M. (2008). Technologies for lifelong kindergarten. Educational Technology Research and Development, 46(4), 43-55.

xxi. Stanley, W. B. (1991). Teacher competencies for social studies. In Shaver (Ed.). Handbook for research on social studies teaching and learning. New York: Mcmillan Publishing. 